\title{
Necroptosis promotes cell-autonomous activation of proinflammatory cytokine gene expression
}

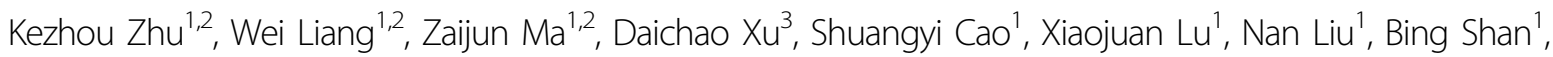 \\ Lihui Qian ${ }^{1}$ and Junying Yuan ${ }^{1,3}$
}

\begin{abstract}
Necroptosis, a form of regulated necrotic cell death, is mediated by receptor interacting protein 1 (RIPK1), RIPK3, and mixed lineage kinase domain-like protein (MLKL). However, the mechanism by which necroptosis promotes inflammation is still unclear. Here we report that the expression of cytokines is robustly upregulated in a cellautonomous manner during necroptosis induced by tumor necrosis factor alpha (TNFa). We demonstrate that TNFainduced necroptosis leads to two waves of cytokine production. The first wave, more transient and weaker than the second, is in response to TNFa alone; whereas the second wave depends upon the necroptotic signaling. We show that necroptosis promotes the transcription of TNFa-target genes in a cell-intrinsic manner. The activation of both NF$\mathrm{KB}$ and $\mathrm{p} 38$ by the necroptotic machinery, RIPK1, RIPK3, and MLKL, is involved in mediating the robust induction of cytokine expression in the second wave. In contrast, necroptosis induced by direct oligomerization of MLKL promotes cytokine production at much lower levels than that of necroptosis induced with TNFa. Thus, we conclude that TNFainduced necroptosis signaling events mediated by RIPK1 and RIPK3 activation, in addition to the MLKL oligomerization, promotes the expression of cytokines involving multiple intracellular signaling mechanisms including NF-KB pathway and p38. These findings reveal that the necroptotic cell death machinery mounts an immune response by promoting cell-autonomous production of cytokines. Our study provides insights into the mechanism by which necroptosis promotes inflammation in human diseases.
\end{abstract}

\section{Introduction}

Necroptosis is a regulated form of necrotic cell death that can be activated when cells are stimulated by the proinflammatory cytokine tumor necrosis factor alpha (TNF $\alpha)$ under apoptosis-deficient conditions ${ }^{1,2}$. While necrosis is known to promote inflammation by the passive release of the damage-associated molecular pattern molecules (DAMPs) from ruptured cell membrane, the

\footnotetext{
Correspondence: Lihui Qian (Ihqian@sioc.ac.cn) or

Junying Yuan (junying_yuan@hms.harvard.edu)

'Interdisciplinary Research Center on Biology and Chemistry, Shanghai Institute of Organic Chemistry, Chinese Academy of Sciences, 26 Qiuyue Rd, PuDong District, 201203 Shanghai, China

University of Chinese Academy of Sciences, 100049 Beijing, China

Full list of author information is available at the end of the article

Edited by T Brunner
}

mechanism by which necroptosis promotes inflammation has not been vigorously examined. In TNF $\alpha$-stimulated cells, necroptosis is activated via the formation of two sequential complexes, complex I and complex IIb. Receptor interacting protein 1 (RIPK1) is recruited into complex I by interacting with the intracellular death domain of TNF receptor 1 (TNFR1). Inhibition of apoptosis promotes the activation of RIPK1. Activated RIPK1 interacts with RIPK3 to induce its phosphorylation and formation of the RIPK1/RIPK3 complex, known as complex $\operatorname{IIb}^{3,4}$. Activated RIPK3 further recruits and phosphorylates the pseudokinase mixed lineage kinase domain-like protein (MLKL). Phosphorylated MLKL in turn oligomerizes and translocates from the cytosol to the plasma membrane to execute cell death ${ }^{5-7}$.

\section{(c) The Author(s) 2018}

(c) (i) Open Access This article is licensed under a Creative Commons Attribution 4.0 International License, which permits use, sharing, adaptation, distribution and reproduction in any medium or format, as long as you give appropriate credit to the original author(s) and the source, provide a link to the Creative Commons license, and indicate if changes were made. The images or other third party material in this article are included in the article's Creative Commons license, unless indicated otherwise in a credit line to the material. If material is not included in the article's Creative Commons license and your intended use is not permitted by statutory regulation or exceeds the permitted use, you will need to obtain permission directly from the copyright holder. To view a copy of this license, visit http://creativecommons.org/licenses/by/4.0/. 


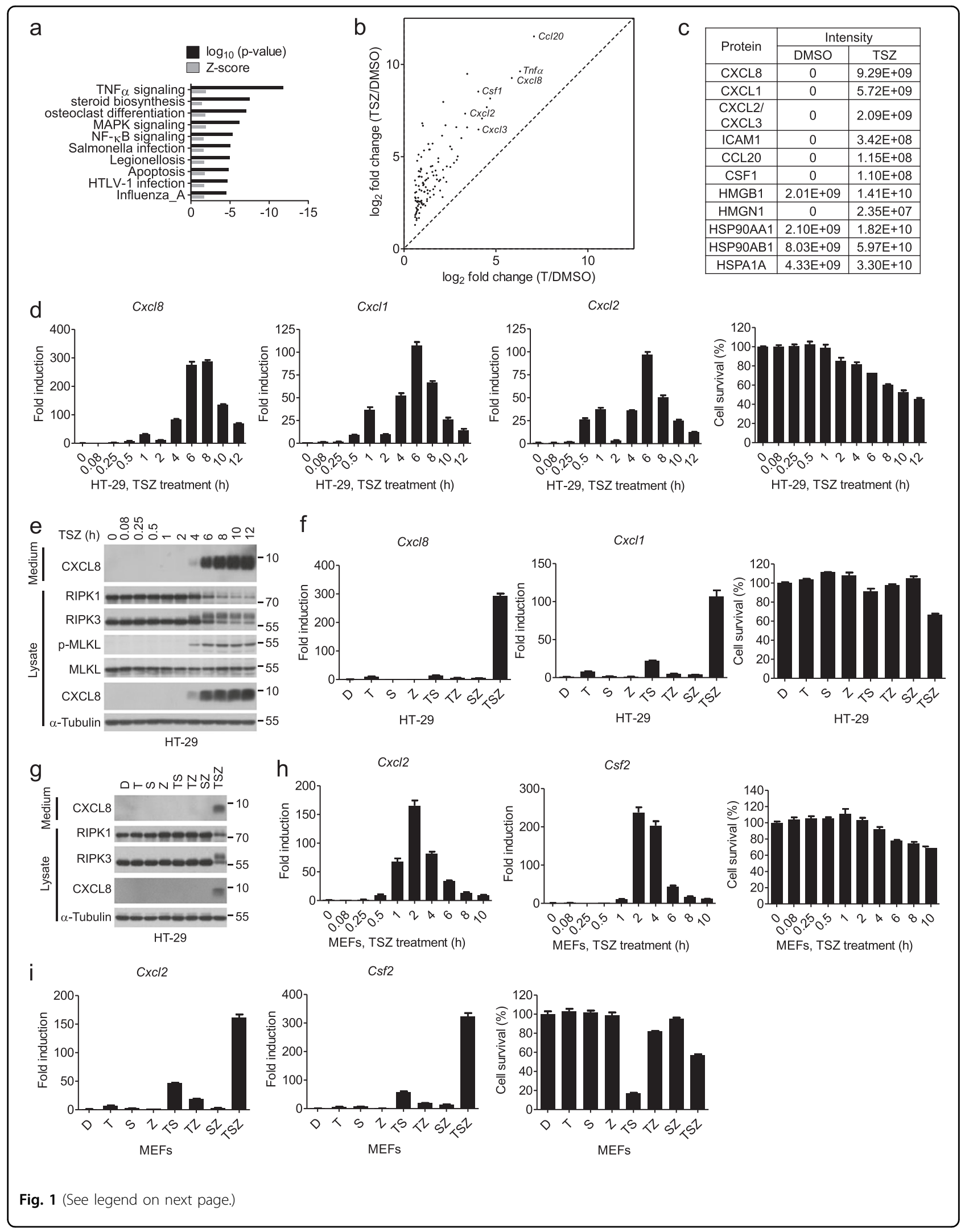




\begin{abstract}
(see figure on previous page)
Fig. 1 Expression of cytokines is highly induced during necroptosis. a The Kyoto Encyclopedia of Genes and Genomes (KEGG) pathway database analysis of the 813 necroptosis-upregulated genes in Enrichr. b Scatterplot of the fold inductions of the overlapping genes induced by TNFa and TSZ. Representative genes were labeled. c Table of selected proteins identified in the media of necroptotic cells by mass spectrometry. Protein abundance was quantified with LFQ module implemented in MaxQuant. $\mathbf{d}$ HT-29 cells were treated with TSZ for the indicated periods of time. $C x C 18, C x C 11$, and CxCl2 mRNA levels were measured by qPCR. The cell viability was determined by CellTiter-Glo. e HT-29 cells were treated with TSZ for the indicated periods of time. The cell lysates and culture media were collected separately, and analyzed by western blotting with indicated antibodies. $\mathbf{f H T}-29$ cells were treated as indicated for $8 \mathrm{~h}$. The expression levels of $\mathrm{CxCl} / 8$ and $\mathrm{CxCl} /$ were analyzed by qPCR. The cell viability was determined by CellTiter-Glo. D, DMSO $(<0.2 \%)$. $\mathbf{g}$ HT-29 cells were treated as indicated for $8 \mathrm{~h}$. The supernatants and cell lysates were collected and analyzed by western blotting. $\mathbf{h}$ MEFs were treated for the indicated periods of time with TSZ. The expression levels of CxCl2 and Csf2 were determined by qPCR. The cell viability was determined by CellTiter-Glo. i MEFs were treated as indicated. CxCl2 and Csf2 mRNA levels were measured by qPCR after $4 \mathrm{~h}$ of treatment. The cell viability was determined by CellTiter-Glo after $13 \mathrm{~h}$ of treatment. Gene expression determined by qPCR was shown as fold induction compared with untreated cells in all figures. All reagents were used at concentrations as described in Materials and Methods in all experiments, unless otherwise noted. Data were presented as mean \pm SEM of triplicates
\end{abstract}

TNF $\alpha$ promotes inflammation via nuclear factor $\kappa \mathrm{B}(\mathrm{NF}-\mathrm{\kappa B})$-regulated transcriptional program ${ }^{8}$. Under basal conditions, NF- $\mathrm{B}$, a dimeric transcription factor complex including the Rel family of proteins, is sequestered in the cytoplasm by inhibitor of NF- $\kappa \mathrm{B}(\mathrm{I} \kappa \mathrm{B})$. RIPK1 acts as a scaffold to activate NF- $k B^{9-11}$. The recruitment and ubiquitination of RIPK1 in the TNF $\alpha$ receptor signaling complex promotes the activation of TGF- $\beta$ activated kinase 1 (TAK1), which in turn phosphorylates and activates $I \kappa B$ kinase $(\mathrm{IKK})$ complex ${ }^{12,13}$. Activated IKKs then phosphorylate $I_{\kappa} B$ to promote its ubiquitination by SCF- $\beta$-TrCP and subsequent degradation through the proteasomal pathway, thereby allowing the NF-kB complex to translocate into the nucleus to activate transcription $^{14-16}$.

Here, we investigate the mechanism by which necroptosis promotes inflammation. We show that TNF $\alpha-$ induced necroptosis signaling events involving RIPK1 and RIPK3 activation, in addition to the MLKL oligomerization, promote the expression of proinflammatory cytokines cell-autonomously through intracellular signaling mechanisms including NF- $\mathrm{kB}$ pathway and p38.

\section{Results}

\section{Upregulation of cytokines during necroptosis}

To characterize the transcriptional changes in necroptotic cells, we stimulated HT-29 cells with TNF $\alpha$ (T), SM$164(\mathrm{~S})$, and a pan-caspase inhibitor zVAD (Z) (TSZ), a well-established protocol to induce TNF $\alpha$-mediated necroptosis, and profiled the transcriptome of necroptotic cells by RNA-sequencing (RNA-seq). Based on the differential gene expression analysis, we identified a transcriptional signature of necroptosis consisting of 813 genes whose expression was upregulated $>1.5$ fold $(n=3$, $p<0.01)$ by TSZ and inhibited $>2$ fold $(n=3, p<0.01)$ by the addition of Nec-1s, a chemical inhibitor of necroptosis against the RIPK1 kinase ${ }^{17,18}$. The most-significantly enriched gene set during necroptosis was associated with the TNF $\alpha$ signaling (Fig. 1a) ${ }^{19,20}$. Consistently, the expression of 116 out of the 813 genes activated by necroptosis was also induced by TNF $\alpha$ alone $(n=3, \mathrm{~T} /$ DMSO $>1.5, p<0.05)$, but at a much lower level than that by TSZ (Fig. 1b). The mRNA levels of proinflammatory cytokines, such as Ccl20, Tnfo, Cxcl8, and Csf1, wellknown TNF $\alpha$ target genes, were the most highly upregulated during necroptosis (Fig. 1b).

We further analyzed the proteins/cytokines released from necroptotic cells using mass spectrometry. Apart from the released intracellular proteins such as high mobility group (HMG) proteins, including HMGB1 and HMGN1 ${ }^{21,22}$, the induction of necroptosis was associated with increased release of cytokines, such as CXCL8, CXCL1, CCL20, and CSF1, in the culture media (Fig. 1c).

We next characterized the temporal profiles of representative cytokine expression by quantitative PCR (qPCR). We found that there were two waves of increases in the mRNA levels of Cxcl8, Cxcl1, and Cxcl2 (Fig. 1d). The first wave increases occurred around $1 \mathrm{~h}$ in HT-29 cells after the addition of TSZ and declined rapidly. The second wave occurred when the cells began to die and corresponded temporally with the phosphorylation of RIPK3 and MLKL (Fig. 1d, e). Compared to that of the first wave, the increased expression of cytokines in the second wave was much more robust and persistent. In contrast to that of necroptotic cells induced by TSZ, the induction of cytokines, such as Cxcls and Cxcl1, was much weaker or not induced at all in cells treated with TNFa alone or SM-164 alone, or in apoptotic cells induced with TNF $\alpha / S M-164$ (TS) (Fig. 1f, g). The time course analysis of cytokine expression stimulated by TNF $\alpha$ and TSZ showed that although a comparable level of cytokine expression was induced by TNF $\alpha$ and TSZ at $1 \mathrm{~h}$ following the treatment, the second wave of cytokine induction in necroptosis was absent in cells stimulated by TNF $\alpha$ alone (Supplementary Figure 1a). Thus, necroptosis enhanced cytokine production by promoting a second wave of cytokine expression that cannot be triggered by TNF $\alpha$ alone. 
To determine if necroptosis is generally associated with increased production of cytokines, we stimulated other cell lines with TSZ to activate necroptosis. We found that the expression of cytokines was induced during necroptosis in mouse embryonic fibroblasts (MEFs), wild-type Jurkat, HT-22, and L929 cells, which synchronized with the progress of cell death (Fig. 1h and Supplementary Figure $1 \mathrm{~b}-\mathrm{e})$. Similarly, the robust induction of $\mathrm{Cxcl} 2$ and Csf 2 was specific to necroptotic cells induced by TSZ as minimal levels of cytokines were detected in MEFs stimulated by other treatments (Fig. 1i and Supplementary Figure 1f). In MEFs, the second wave of cytokine expression induced by TSZ followed immediately the first one (Supplementary Figure 1f).

We further verified that cytokine production could be induced in necroptosis triggered by stimuli other than TSZ. We found that cytokine expression could be induced during necroptosis of FADD-deficient Jurkat cells with TNF $\alpha$ alone, as well as HT-29 cells and wild-type Jurkat cells with a combination of TRAIL, SM-164, and zVAD (Supplementary Figure 1g-i). Taken together, these results suggest that the expression of proinflammatory cytokines can be induced in multiple necroptosis models.

\section{$\mathrm{NF}-\mathrm{KB}$ is required for cytokine induction during necroptosis}

Since the inhibition of transcription by actinomycin D blocked the expression of cytokines induced by necroptosis (Supplementary Figure 2), we focused our analysis on the known transcriptional mechanisms. We first tested whether the NF- $\kappa B$ pathway activated by TNF $\alpha$ was involved. We found that TSZ led to two waves of phospho-p65 and phospho-IkB $\alpha$, key signal transduction events for the activation of NF-kB (Fig. 2a and Supplementary Figure 3a). Furthermore, we found that the addition of TAK1 inhibitor (5Z)-7-Oxozeaenol (5Z-7) and IKK inhibitor TPCA-1 abolished the induction of the cytokines by TSZ (Fig. 2b, c, and Supplementary Figure $3 \mathrm{~b}-\mathrm{d}$ ), suggesting that the activation of the IKK complex is required for cytokine expression during necroptosis.

To examine if the activation of IKKs is required for the second wave of cytokine production during necroptosis independent of the first wave, we delayed the addition of TAK1 and IKK inhibitors to specifically block the second wave of IKK activation and found that delayed inhibition of IKK still could block the second wave of cytokine expression and phosphorylation of p65 and IкB $\alpha$ (Supplementary Figure $3 \mathrm{e}-\mathrm{i})$. Furthermore, blocking NF- $\mathrm{kB}$ activation by either overexpression of the ІкB $\alpha$ superrepressor (IkB $\alpha-S R$ ) with the S32A/S36A double mutation, and therefore resistant to degradation ${ }^{23}$, or knockdown of p65 by short hairpin RNA (shRNA) completely abrogated cytokine expression in HT-29 cells and MEFs treated with TSZ without effects on cell death (Fig. 2d-f). Collectively, these data suggest that NF- $\mathrm{kB}$ is required for the second wave of cytokine expression during necroptosis.

To examine whether there are additional mechanisms underlying the cytokine induction during necroptosis, we evaluated the potential roles of MAPKs, such as p38 and JNK activated during necroptosis (Supplementary Figure $3 \mathrm{a})^{24}$, and the noncanonical NF- $\mathrm{kB}$ pathway. The JNK inhibitor SP600125 did not inhibit the cytokine induction during necroptosis (Supplementary Figure 4a). Inhibition of p38 activity by PH-797804 or silencing p38 $\alpha$, the most abundant p38 member, resulted in a moderate reduction of cytokine expression by $20-50 \%$ (Supplementary Figure $4 \mathrm{a}, \mathrm{b})$. Smac mimetics had been reported to activate the noncanonical NF-kB pathway ${ }^{25,26}$. However, knockdown of RELB, a key mediator of noncanonical NF- $\mathrm{kB}$ pathway, not only did not block chemokine expression, but rather promoted Cxcl1 expression to some extent (Supplementary Figure 4c). These results indicate that the activation of both canonical NF- $\mathrm{kB}$ and p38 is involved in mediating cytokine induction during necroptosis.

\section{The RIPK1-RIPK3-MLKL axis is essential for the induction of cytokines during necroptosis}

We next examined the involvement of necroptotic machinery in the production of cytokines. Interestingly, we found that cytokine inductions by necroptosis were inhibited by Nec-1s (an inhibitor of RIPK1), GSK872 (an inhibitor of RIPK3), and necrosulfonamide (NSA, an inhibitor of human MLKL oligomerization) (Fig. 3a-c and Supplementary Figure $1 \mathrm{~g}-\mathrm{i}, 5 \mathrm{a}-\mathrm{d})^{17,27,28}$. In addition, knockdown of RIPK1, RIPK3, and MLKL reduced the production of cytokines (Fig. 3d-g and Supplementary Figure 5e-h). On the other hand, inhibition of RIPK1, RIPK3, or MLKL failed to block the first peak of Cxcl8 expression induced by TSZ, or the expression of cytokine induced by TNF $\alpha$ alone or TS in HT-29 cells (Supplementary Figure 6a-d). Also, MLKL ablation did not affect the induction of $\mathrm{Cxcl} 8$ and $\mathrm{Cxcl} 1$ by TNF $\alpha$ alone or TS (Supplementary Figure 6e). Thus, the RIPK1-RIPK3-MLKL axis is specifically required for the necroptosis-induced cytokine production.

\section{Cell-autonomous induction of cytokines during necroptosis}

We next asked whether RIPK1-RIPK3-MLKL induced cytokines in a cell-autonomous manner, or indirectly by the release of DAMPs, which might trigger cytokine expression in a paracrine manner (Fig. 4a). To address this question, we treated naive HT-29 cells with conditioned medium from necroptotic cells and compared the time course of the cytokine induction with that directly induced by TSZ (Fig. 4b). We found that the conditioned medium from TSZ-treated HT-29 cells did not accelerate 


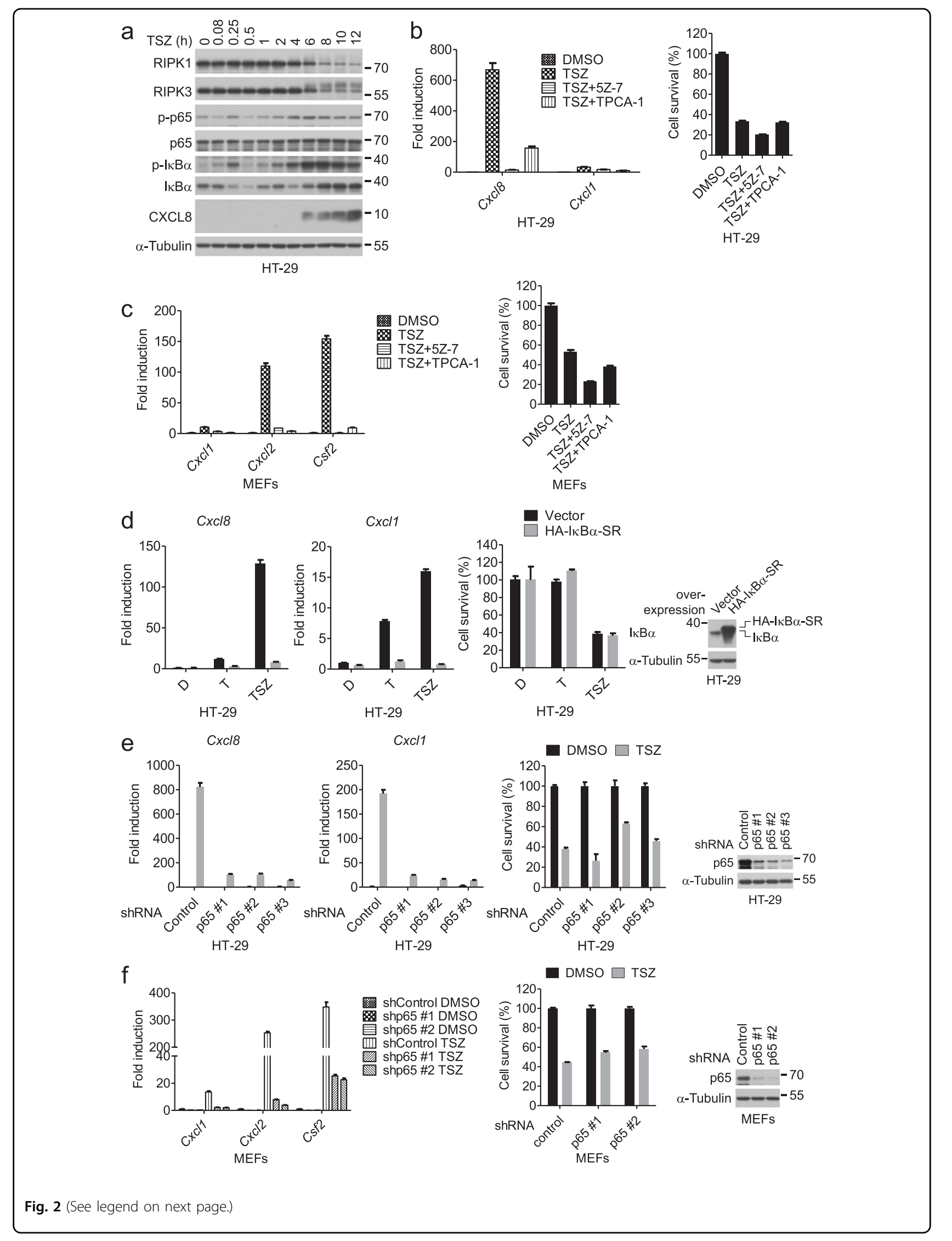




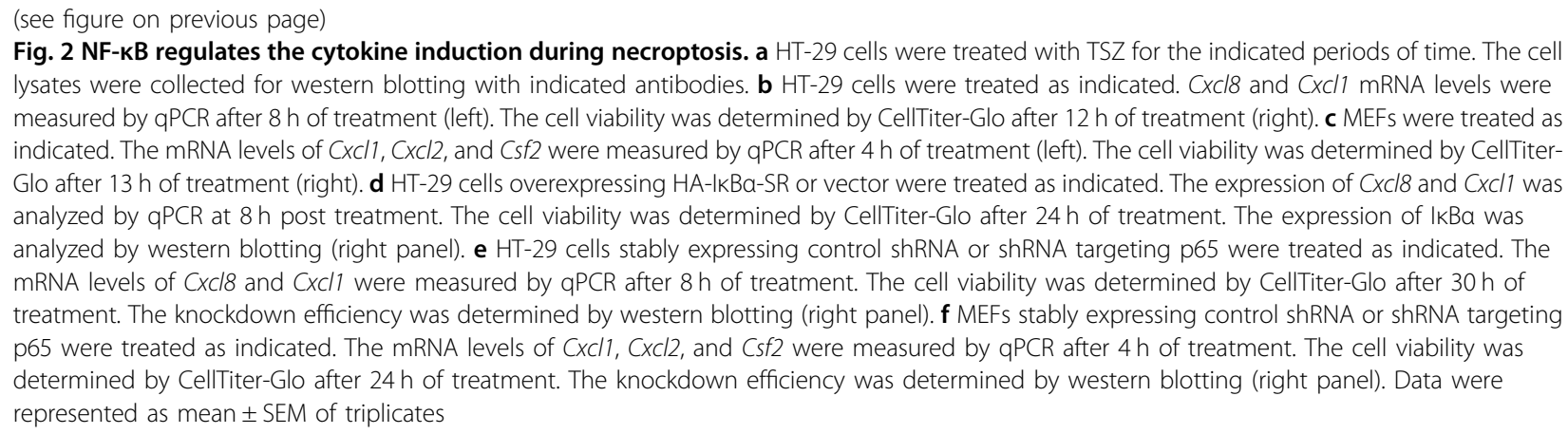

cytokine production as it still took $8 \mathrm{~h}$, the same amount of time as that of inducing the expression of $\mathrm{Cxcl} 8$ by TSZ (Fig. 4c). In addition, the conditioned medium from necroptotic cells did not compromise the ability of Nec-1s to inhibit $\mathrm{Cxcl}$ expression in naive cells (Fig. 4c). Thus, the released DAMPs from necroptotic cells are unlikely to be sufficient to induce the expression of cytokines.

To determine if the interaction of dying cells with neighboring cells was required for the induced expression of cytokines, we co-cultured cell death-deficient shMLKL HT-29 cells and NF-kB-deficient shp65 HT-29 cells. Most notably, after necroptosis induction, the mixed culture of shMLKL cells and shp65 cells was still unable to induce the expression of $\mathrm{Cxcl} 8$ and $\mathrm{Cxcl1}$ as that of shControl cells (Fig. 4d, e), suggesting that any factors from dying shp65 cells could not complement MLKL knockdown to induce cytokine expression.

To further evaluate the role of DAMPs and cell-cell interactions in cytokine production during necroptosis, we co-cultured mCherry marked shControl and GFP marked shMLKL HT-29 cells in 1:1 ratio so that they could be treated in the same well and then separated according to their fluorescent markers by FACS for analyzing the expression of cytokines (Fig. 4f, g). Consistently, the mRNA levels of cytokines in necroptotic shControl cells were much higher than that of shMLKL cells treated with TSZ (Fig. 4h).

Finally, we assayed the cytokine production in the detached dead HT-29 cells treated with TSZ. We found that the expression of cytokines in the detached cells was higher than that of the attached cells (Fig. 4i), consistent with induction of cytokine expression in necroptotic cells. From these results, we conclude that the expression of cytokines during necroptosis is induced in a cellautonomous manner.

\section{The RIPK1-RIPK3-MLKL axis is required for nuclear entry of p65}

We next compared the NF- $\mathrm{kB}$ activation between TSZ and TNF $\alpha$ treatment. Consistent with the magnitude of cytokine induction, the second peak of phosphorylation of p 65 and IkB $\alpha$ during necroptosis was much stronger than that triggered by TNF $\alpha$ alone (Fig. 5a and Supplementary Figure 7a). In line with the requirement for the scaffolding function of RIPK1, but not its kinase activity, in activating $\mathrm{IKK}^{29}$, knockdown of RIPK1, but not its kinase inhibitor Nec-1s, blocked the IKK-mediated p65 and IкB $\alpha$ phosphorylation during necroptosis (Fig. 5b, c). Similarly, we found that neither the treatment of additional necroptosis inhibitors, including the RIPK3 inhibitor GSK872 and the MLKL inhibitor NSA, nor the silencing of RIPK3 and MLKL had any inhibitory effect on the phosphorylation of I $\mathrm{B} \alpha \alpha$ or p65 induced by TSZ (Fig. 5d, e and Supplementary Figure $7 \mathrm{~b}-\mathrm{f}$ ). Consistent with a role of p38 in cytokine production, phosphorylation of $\mathrm{p} 38$, the hallmark for p38 activation, was attenuated by necroptosis inhibitors (Fig. 5d).

Because I $\mathrm{K} B \alpha$ is degraded upon its phosphorylation by IKK, we further determined the kinase activity of IKK with a fusion GST-IKB $\alpha$ substrate using the IKK complex immunoprecipitated from the cells treated with TSZ in the presence or absence of necroptosis inhibitors. Inhibition of RIPK1, RIPK3, or MLKL could not block the IKK activity in the in vitro kinase assay (Fig. 5f). Taken together, these results suggest that the RIPK1 kinase activity, RIPK3, and MLKL enhance p38 activation and the NF$\kappa \mathrm{B}$-dependent transcription downstream of IKK activation during necroptosis.

We next examined the nuclear translocation of p65, during necroptosis, a critical event for NF- $\mathrm{kB}$. Similar to that of cytokine induction, two waves of p65 nuclear translocation occurred during TSZ-induced necroptosis (Fig. 5g). An early transient nuclear import of p65 was observed at 15 and $30 \mathrm{~min}$ after TSZ stimulation, and a delayed and prolonged nuclear translocation of p65 occurred at $4 \mathrm{~h}$ after TSZ treatment and lasted for $4 \mathrm{~h}$. In contrast, only a brief nuclear accumulation was found in cells stimulated by TNFo alone at 15 and $30 \mathrm{~min}$ after stimulation (Fig. 5g). Thus, necroptosis is characterized with a sustained p65 nuclear translocation that is 


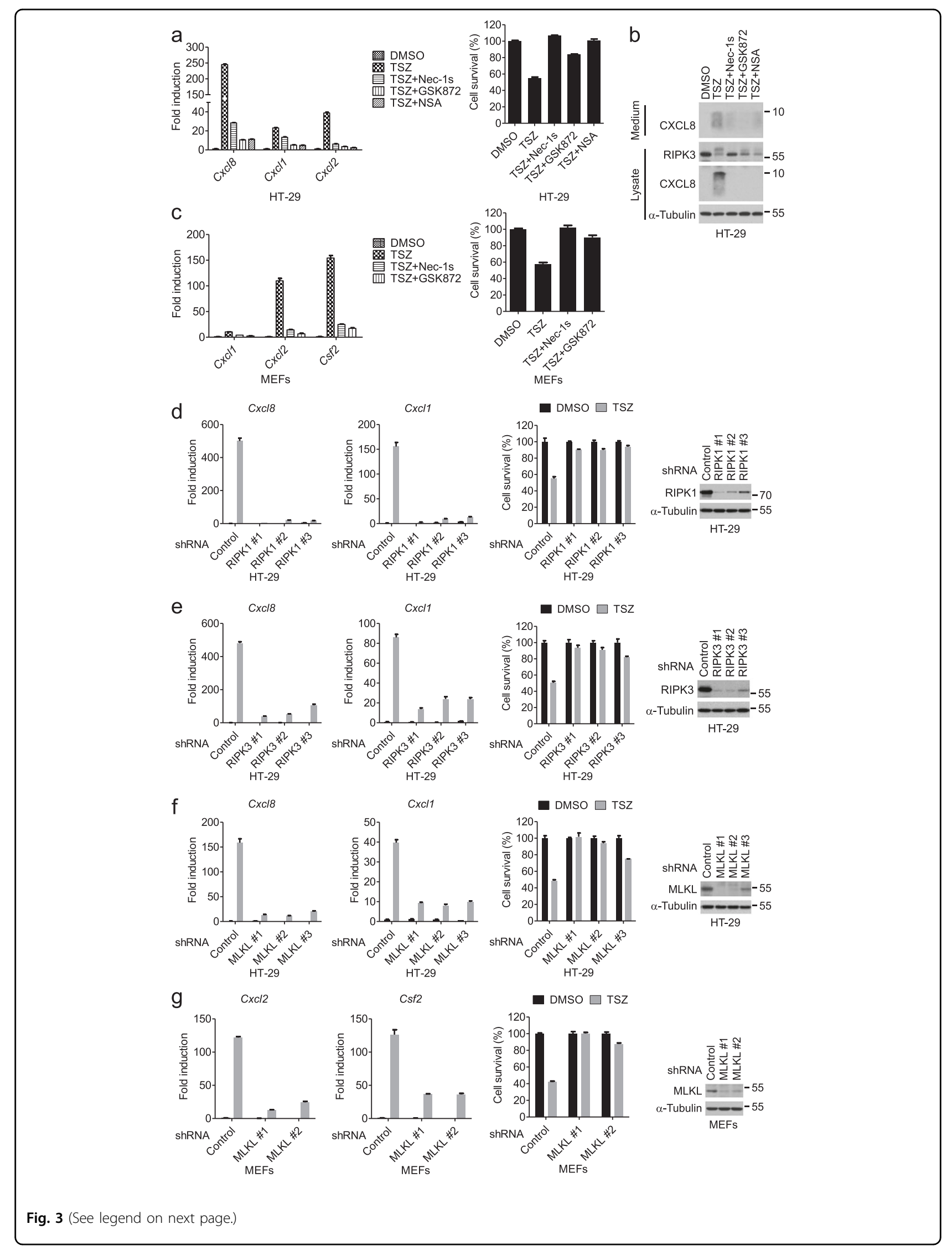


(see figure on previous page)

Fig. 3 The RIP1-RIP3-MLKL axis is required for the induction of cytokines associated with necroptosis. a HT-29 cells were treated as indicated. The mRNA levels of $C x c / 8$ and $C x c / 1$ were measured by qPCR after $8 \mathrm{~h}$ of treatment (left). The cell viability was determined by CellTiter-Glo after $24 \mathrm{~h}$ of treatment (right). $\mathbf{b} \mathrm{HT}-29$ cells were treated as indicated for $8 \mathrm{~h}$. Cell culture medium and cell lysates were collected separately, followed by western blotting analysis. c MEFs were treated as indicated. The mRNA levels of Cxcl1, Cxcl2, and Csf2 were measured by qPCR after $4 \mathrm{~h}$ of treatment (left). Cell viability was determined by measuring ATP levels after $13 \mathrm{~h}$ of treatment (right). $\mathbf{d}-\mathbf{f} \mathrm{HT}-29$ cells stably expressing the indicated shRNA were treated with DMSO or TSZ. The mRNA levels of $C x c l 8$ and $C x c 17$ were measured by qPCR after $8 \mathrm{~h}$ of treatment. The cell viability was determined by CellTiter-Glo after $24 \mathrm{~h}$ of treatment. The knockdown efficiency was determined by western blotting. $\mathbf{g}$ MEFs stably expressing the indicated shRNA were treated with DMSO or TSZ. The mRNA levels of Cxcl2 and Csf2 were measured by qPCR after $4 \mathrm{~h}$ of treatment. The cell viability was determined by CellTiter-Glo after $22 \mathrm{~h}$ of treatment. The knockdown efficiency was determined by western blotting. Data were represented as mean \pm SEM of triplicates

correlated temporally with the cell death and robust cytokine gene expression during the second wave. We next asked whether the RIPK1-RIPK3-MLKL axis was required for the necroptosis-specific nuclear entry of p65. We found that the inhibition of RIPK1 kinase by Nec-1s, RIPK3 by GSK872, or MLKL by NSA prevented the translocation of p65 into the nucleus (Fig. 5h). Thus, necroptotic machinery promotes the sustained nuclear entry of p65 to activate the cytokine expression during necroptosis.

\section{Degradation of $\mathrm{IKBa}$ is regulated by the RIPK1-RIPK3-MLKL axis during necroptosis}

The $\beta$-TrCP-mediated ubiquitination and the subsequent proteasomal degradation of $\mathrm{I} \kappa \mathrm{B} \alpha$ is known to be the prerequisite for the $\mathrm{p} 65 / \mathrm{p} 50$ translocation to nucleus $^{14-16,30}$. Consistently, either knockdown of $\beta$ TrCP2 or the delayed addition of MG132 blocked Cxcl8 and Cxcl1 expression during necroptosis (Fig. 6a, b). However, no obvious difference of $I_{\kappa} B \alpha$ protein levels was found between cells treated with TSZ and TSZ plus necroptosis inhibitors (Fig. 5d and Supplementary Fig-

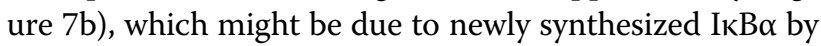
$\mathrm{NF}-\kappa \mathrm{B}$. Indeed, the transcription of ІкB $\alpha$ was induced during necroptosis in a RIPK1-RIPK3-MLKL-dependent manner (Supplementary Figure 8a-g).

We next expressed an exogenous IкB $\alpha$ lacking the NF$\kappa \mathrm{B}$ response element to directly monitor the protein turnover of IкB $\alpha$. Similar to endogenous IкB $\alpha$, the phosphorylation and degradation of exogenous ІкB $\alpha$ occurred with two peaks; however, the protein level of exogenous ІкB $\alpha$ was not restored in the second peak (Fig. 6c and

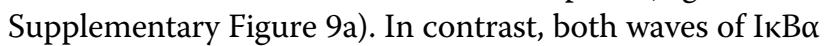
degradation were abolished by the S32A/S36A mutation in IKK-mediated phosphorylation sites as well as the $\mathrm{K} 21 \mathrm{R} / \mathrm{K} 22 \mathrm{R}$ mutation in $\mathrm{SCF}^{\beta-\operatorname{TrCP}}$-dependent ubiquitination sites (Supplementary Figure 9b). Furthermore, compared to that of TNF $\alpha$ or TS, necroptosis induced a more pronounced decrease of exogenous ІкB $\alpha$ protein at the second peak, which could be blocked by necroptosis inhibitors as well as by the IKK inhibitor TPCA-1 (Fig. 6d, e). On the other hand, the first wave of IкB $\alpha$ degradation was blocked by TPCA-1 but not by necroptosis inhibitors (Supplementary Figure 9c-e), and TNFo alone induced IкB $\alpha$ degradation was not affected by NSA (Supplementary Figure 9f), indicating that the RIPK1 kinase activity, RIPK3, and MLKL were specifically required for the second wave of IKB $\alpha$ degradation.

Since IкB $\alpha$ was degraded through the proteasomal pathway after its ubiquitination, we characterized the ubiquitination of IкB $\alpha$ during necroptosis. We found that I $\mathrm{B} \alpha$ ubiquitination in cells treated with TSZ was significantly stronger than that induced by TNFa alone, which was blocked by IKK inhibition, and by Nec-1s, GSK872, NSA, or silencing MLKL (Fig. 6f-h). Overall, these results indicated that the RIPK1-RIPK3-MLKL axis promoted I $\mathrm{K} \mathrm{\alpha} \alpha$ degradation mediated by ubiquitination.

\section{Necroptosis induced by MLKL oligomerization is weak in promoting cytokine expression}

Oligomerization of MLKL is essential for necroptosis. To assess whether MLKL oligomers are sufficient for cytokine induction during necroptosis, we constructed an induced-active (ac) form of MLKL (acMLKL) by fusing tandem dimerization domains, FKBP (F36V), to the Cterminus of the constitutively active human T357E/S358D double mutant, which could oligomerize upon the addition of the dimerizer, AP20187 (Fig. 7a). Indeed, the induction of MLKL dimerization led to considerable amount of cell death inhibitable by NSA, an inhibitor of MLKL oligomerization, but not by RIPK1 inhibitor Nec1s, the RIPK3 inhibitor GSK872, or caspase inhibitor zVAD (Fig. 7b, c). We found that the induction of MLKL dimerization led to an increase in the mRNA levels of Cxcl 8 that was blocked by NSA but not Nec-1s, GSK872, or zVAD (Fig. $7 \mathrm{~d}-\mathrm{f}$ ). The expression of $\mathrm{Cxcl}$ induced by MLKL dimerization was much lower than that induced by TSZ (Fig. 7f), indicating that necroptosis execution induced by oligomerization of MLKL alone cannot account for the robust induction of cytokines by TSZ. However, TSZ-induced cytokine production in the presence of forced MLKL oligomerization was completely blocked by the IKK inhibitor TPCA-1 and the MLKL inhibitor NSA, and partially inhibited by $\mathrm{Nec}-1 \mathrm{~s}$ and 

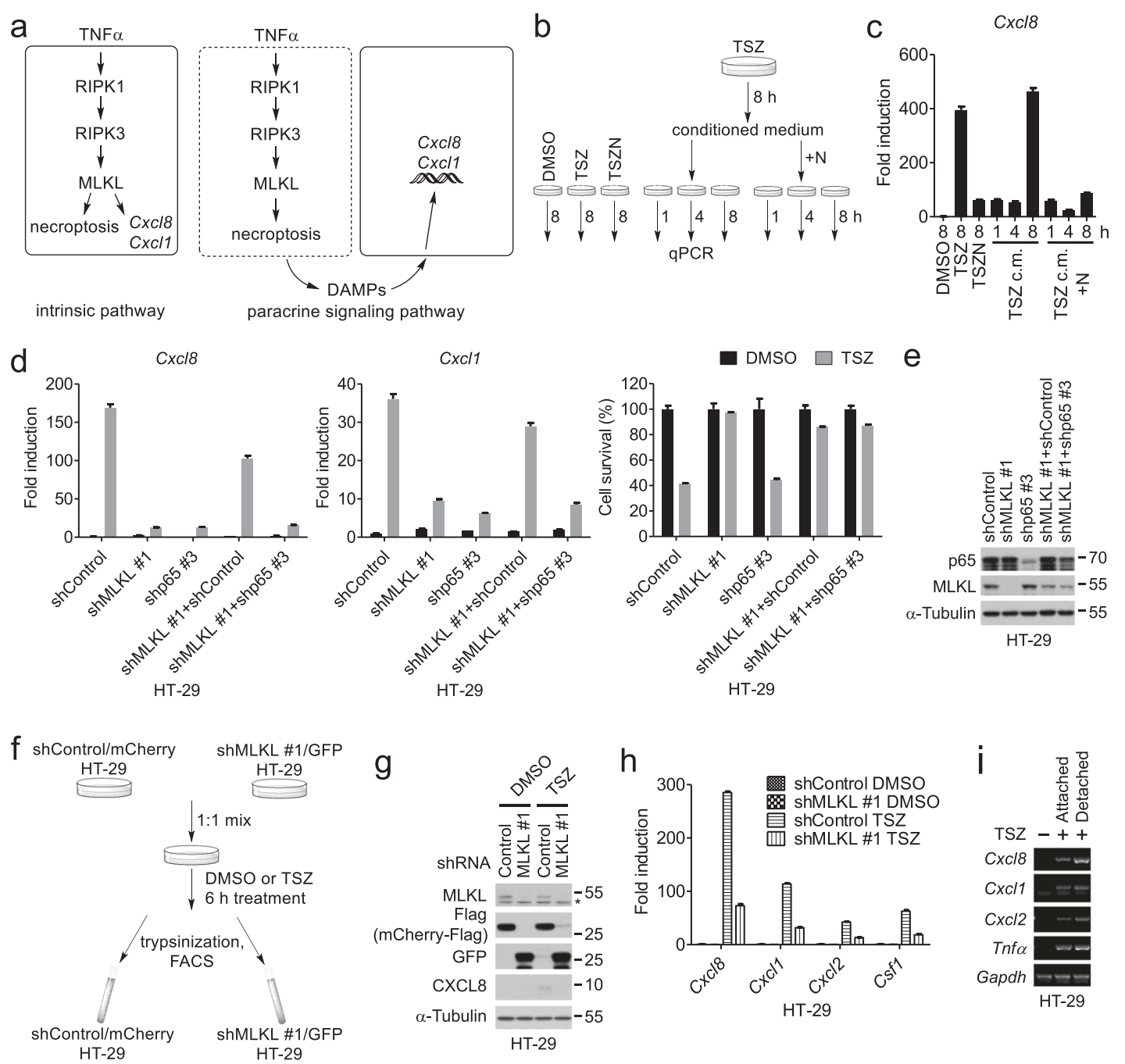

Fig. 4 Cytokine production during necroptosis is mediated by a cell intrinsic pathway. $\mathbf{a}$ The cell-intrinsic and paracrine signaling hypothesis. $\mathbf{b}$ Schematic of the treatments for HT-29 cells with indicated compound(s) or conditioned medium. N, $10 \mu \mathrm{M} \mathrm{Nec-1s.} \mathrm{c} \mathrm{HT-29} \mathrm{cells} \mathrm{were} \mathrm{treated} \mathrm{as}$ shown in $\mathbf{b}$. The expression of Cxcl8 was determined by qPCR; C.m., conditioned medium. d, e HT-29 cells expressing MLKL shRNA or p65 shRNA were cultured individually or co-cultured in a ratio 1:1, and stimulated with DMSO or TSZ. The mRNA levels of CxCl8 and Cxcl1 were measured by qPCR after $8 \mathrm{~h}$ of treatment and the cell viability was determined by CellTiter-Glo after $29 \mathrm{~h}$ of treatment (d). The protein levels of p65 and MLKL were analyzed by western blotting (e). f Schematic of the co-culture and FACS experiment. HT-29 cells were treated with DMSO or TSZ for $6 \mathrm{~h}$, and then separated by FACS to obtain Cherry+ (shControl) or GFP+ (shMLKL) populations. g Western blotting analysis of lysates from HT-29 cells separated in $\mathbf{f}$. Asterisk indicates nonspecific bands. $\mathbf{h}$ Quantitative PCR analysis of CxCl8, Cxcl1, CxCl2, and Csf1 mRNA levels in HT-29 cells derived from $\mathbf{f}$. i The expression of the cytokines was determined by RT-PCR in the attached or detached HT-29 cells after $8 \mathrm{~h}$ treatment with TSZ

GSK872 ( 50\%) (Fig. 7g). On the other hand, TNF $\alpha$ alone cannot enhance the cytokine expression in cells with MLKL oligomers (Supplementary Figure 10). Therefore, in addition to MLKL oligomers, RIPK1- and RIPK3activated signaling events as well as IKK activation mediated by TNF $\alpha$ signaling may contribute to the robust cytokine expression during TSZ-induced necroptosis.

\section{Discussion}

Necrosis is known to be proinflammatory from the passive leakage of DAMPs due to disrupted cytoplasmic membrane. However, the discovery of necroptosis, a regulated necrotic cell death mechanism, raised the question if there is an active program that can promote inflammation during necroptosis, i.e., inflammation beyond that activated by the passive release of intracellular content alone. Through a comparative transcriptome analysis of TNF $\alpha$-induced necroptosis in the presence or absence of the RIPK1 kinase inhibitor Nec-1s, we discovered that necroptosis exerts a profound effect on transcription, activating the expression of a large number of genes. Notably, many of the upregulated genes, such as 


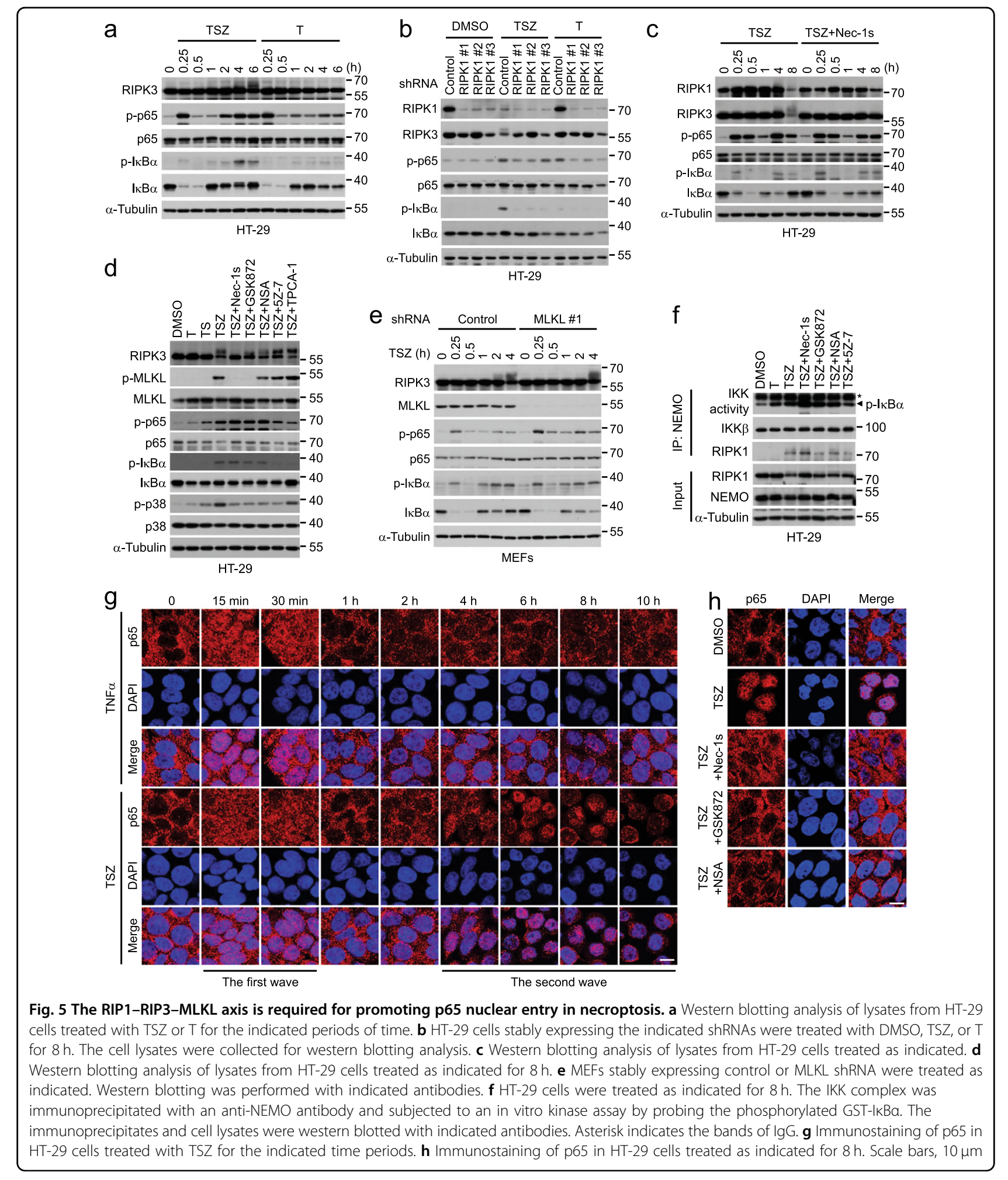

inflammatory cytokines, are in common with the target genes of TNF $\alpha$ pathway and all of them were expressed at a substantially higher level during necroptosis than that triggered by TNF $\alpha$. These results suggest that necroptosis enhances TNF $\alpha$-induced gene transcription. The greatly elevated cytokine expression appears to be a common feature of necroptosis as it was found in a panel of necroptotic cell lines and can be activated by different 


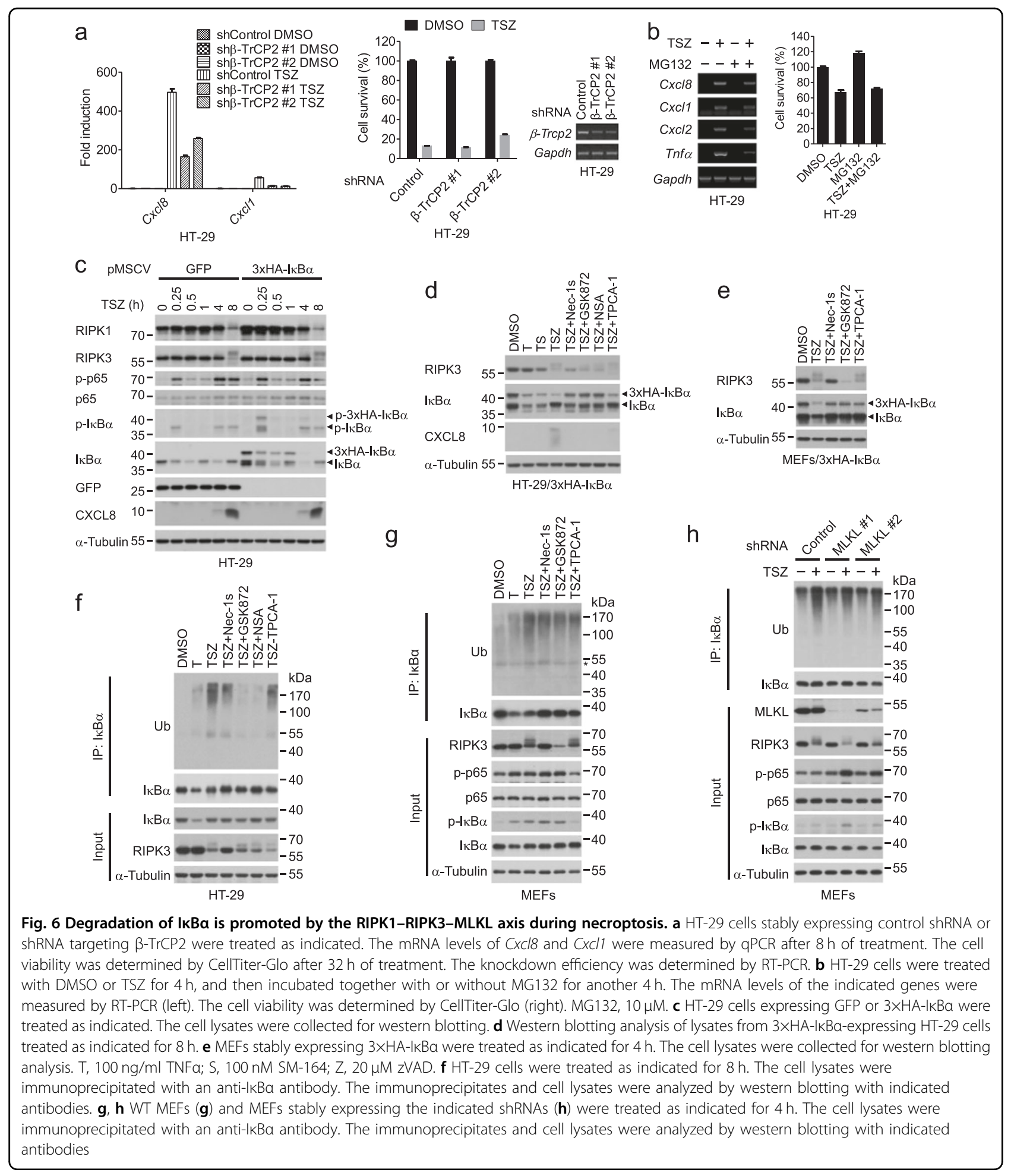

types of necroptotic stimuli including TNFa and TRAIL. The overrepresentation of TNF $\alpha$ target genes in the necroptosis-upregulated genes provides compelling evidence to show that necroptosis exacerbates TNF $\alpha$ mediated inflammation. Although DAMPs can promote inflammation, we demonstrated that the increased cytokine production in TNF $\alpha$-induced necropotosis is independent of DAMPs release and requires cell-intrinsic activation of NF-kB and p38. Future studies will be needed to explore the transcriptional regulatory mechanisms 

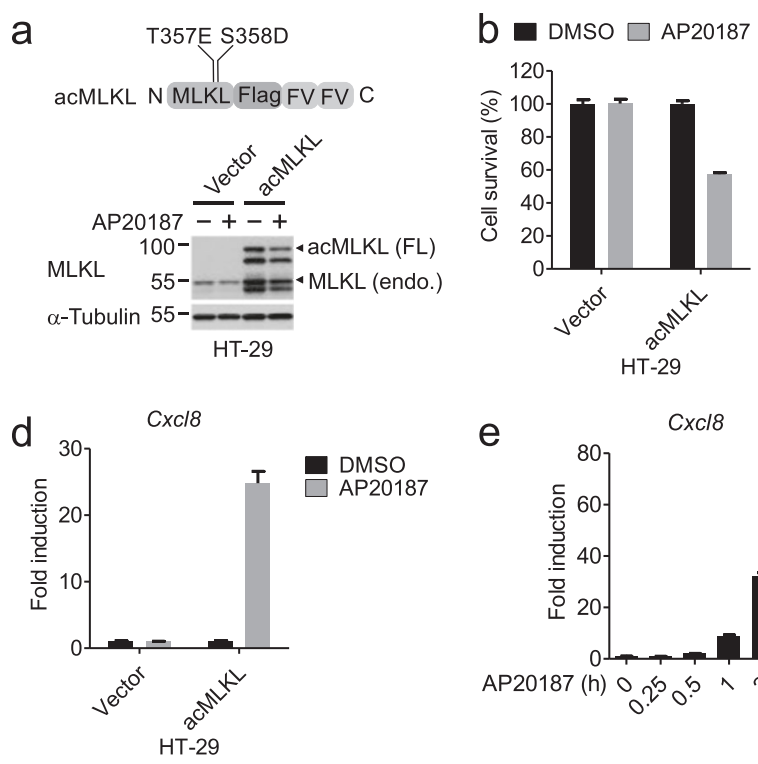

e
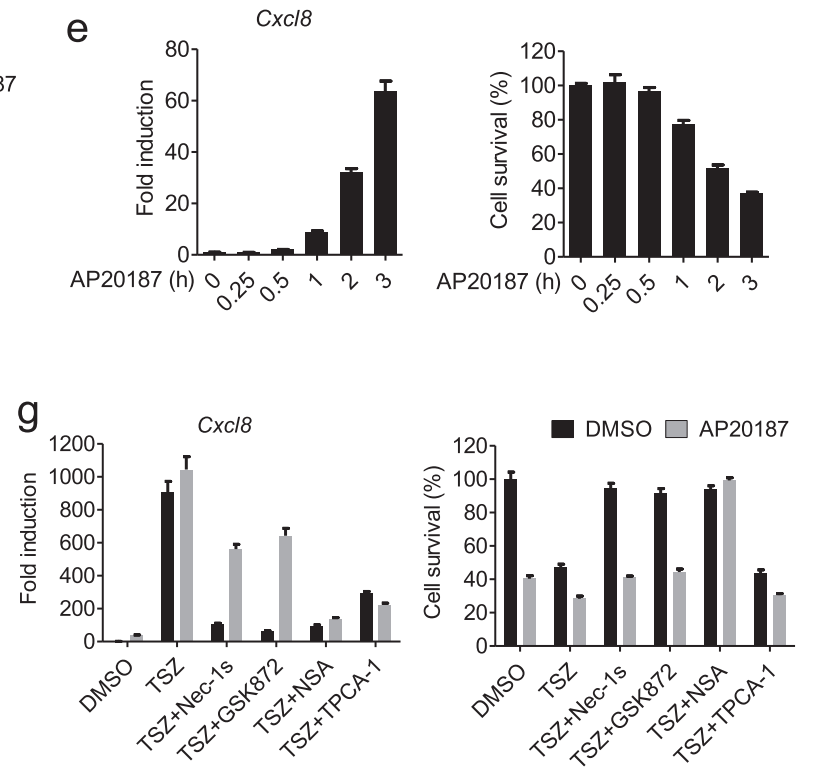

Fig. 7 Necroptosis induced by forced dimerization of MLKL is much less effective in inducing cytokine production than that by TSZ. a Schematic representation of the oligomerizable MLKL (acMLKL) (upper) and western blotting analysis of lysates from HT-29 cells stimulated with DMSO or AP20187 for $2 \mathrm{~h}$ (lower). FL, full length; endo., endogenous. b HT-29 cells stably expressing the indicated constructs were stimulated with DMSO or AP20187 for $2 \mathrm{~h}$. The cell viability was determined by CellTiter-Glo. c HT-29 cells expressing acMLKL were treated with the indicated compounds for $6 \mathrm{~h}$ except AP20187, which was administered in the last $2 \mathrm{~h}$. The cell viability was determined by CellTiter-Glo. d HT-29 cells stably expressing the vector or acMLKL were stimulated with DMSO or AP20187 for $2 \mathrm{~h}$. Cxcl8 mRNA levels were measured by qPCR. e HT-29 cells stably expressing acMLKL were stimulated with AP20187 for the indicated time. The expression of Cxcl8 was measured by qPCR (left). Cell viability was determined by CellTiter-Glo (right). f The acMLKL expressing HT-29 cells were treated with the indicated compounds for $6 \mathrm{~h}$ except AP20187, which was added during the last $2 \mathrm{~h}$ of incubation. The expression of $\mathrm{CxC} / 8$ was measured by $\mathrm{qPCR}$. $\mathbf{g} \mathrm{HT}$ - 29 cells stably expressing acMLKL were treated as indicated for $8 \mathrm{~h}$ except AP20187. AP20187 was administered in the last $2 \mathrm{~h}$. The expression of CxCl8 was measured by qPCR. The cell viability was determined by CellTiter-Glo. Data were represented as mean \pm SEM of triplicates

that control the induction of proinflammatory cytokine expression by necroptosis.

We showed that cytokine production mediated by MLKL oligomerization alone was substantially lower than that induced by TSZ. This result suggests that MLKL oligomers are necessary but insufficient for maximum cytokine production in necroptosis and events upstream of MLKL oligomerization are required. Mechanistically, we propose that the RIPK1 kinase-RIPK3-MLKL axis does not induce the activity of the IKK complex, but rather activates $\mathrm{p} 38$, and promotes the ubiquitination and

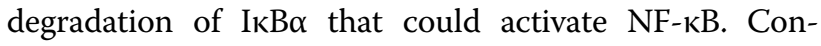
sistently, a much higher level of ubiquitinated I $\mathrm{I} B \alpha$ is induced by TSZ than that by TNF $\alpha$. Therefore, the necroptosis machinery likely acts downstream of IKK to sustain the activation of NF- $\kappa B$. However, as we were not able to detect an association of RIPK1, RIPK3, or MLKL with $I \kappa B \alpha$, necroptosis might promote I $\kappa \mathrm{B} \alpha$ degradation via an indirect mechanism. Taken together, we propose that TNF $\alpha$-mediated necroptosis dependent on RIPK1, RIPK3, and MLKL activation triggers enhanced inflammatory cytokine gene transcription through a cellautonomous mechanism involving NF- $\mathrm{kB}$ and $\mathrm{p} 38$. However, we do not exclude that other mechanisms might also exist in necroptotic cells underlying the cellintrinsic activation of cytokine expression.

Studies in mouse models of human diseases have demonstrated an important role of necroptosis in a variety 
of diseases including inflammatory diseases, neurodegeneration, and cancer ${ }^{31-35}$. As a result, RIPK1 kinase inhibitors have been advanced into the human clinical trial for the treatment of colitis, amyotrophic lateral sclerosis, and Alzheimer's diseases ${ }^{36,37}$. Our study suggests that the enhancement of NF- $\mathrm{kB}$ activation by necroptosis could contribute to the pathogenesis by mediating the production of proinflammatory cytokines, which may serve as biomarkers to monitor the efficacy of therapeutic interventions by inhibition of RIPK1.

\section{Materials and methods}

\section{Reagents and antibodies}

Recombinant human TNF $\alpha$ (Cat\# C008) was purchased from Novoprotein Scientific Inc. (Summit, NJ, USA). Recombinant human TRAIL (Cat\# 375-TL) was obtained from R\&D Systems (Minneapolis, MN, USA). MG132 and zVAD were purchased from Selleckchem (Houston, TX, USA). GSK872 and NSA were purchased from Calbiochem (San Diego, CA, USA). 5Z-7-Oxozeaenol was purchased from Sigma-Aldrich (St. Louis, MO, USA). TPCA1, SP600125, PH-797804, and AP20187 were purchased from MedChemexpress (Princeton, NJ, USA). R-7-Cl-ONec-1 (Nec-1s) and SM-164 were custom synthesized.

Antibodies used in the study were IкB $\alpha$ (C-21, Cat\# sc371), p65 (C-20, Cat\# sc-372), Ub (P4D1, Cat\# sc-8017), NEMO (FL-491, Cat\# sc-8330), and GFP (FL, Cat\# sc8334) from Santa Cruz (Dallas, TX, USA); ІкB $\alpha$ (Cat\#

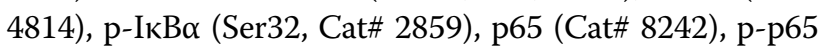
(Ser536, Cat\# 3033), IKK $\beta$ (Cat\# 8943), RIPK1 (Cat\# 3493), and p38 (Cat\# 9212) from Cell Signaling (Danvers, MA, USA); FLAG (Cat\# F3040) from Sigma-Aldrich (St Louis, MO, USA); CXCL8 (Cat\# 17038-1-AP) from Proteintech (Chicago, IL, USA); and $\alpha$-Tubulin (Cat\# PM054) from MBL (Woburn, MA, USA). Antibodies including RIPK3 (Cat\# ab72106), MLKL (Cat\# ab183770), and pMLKL (Ser358, Cat\# ab187091) were obtained from Abcam (Cambridge, UK) to detect human proteins. AntiRIPK3 and anti-MLKL antibodies were produced inhouse to probe the mouse proteins. HRP conjugated goat anti-rabbit IgG $(\mathrm{H}+\mathrm{L})$ secondary antibody (Cat\# 31460) and HRP conjugated goat anti-mouse IgG $(\mathrm{H}+\mathrm{L})$ secondary antibody (Cat\# 31430) were purchased from Thermo Fisher Scientific (Waltham, MA, USA).

\section{Cell culture and treatments}

HT-29 cells were cultured in McCoy's 5A medium (GIBCO, Grand Island, NY, USA), supplemented with 10\% FBS (Biowest, Nuaillé, France) and 1\% penicillin and streptomycin. MEFs, HEK293T, HT-22, and L929 cells were cultured in DMEM (GIBCO) supplemented as described above. Jurkat cells were cultured in RPMI 1640 medium (GIBCO) supplemented as described above. Cells were cultured at $37^{\circ} \mathrm{C}$ in a humidified atmosphere with $5 \% \mathrm{CO}_{2}$.
For HT-29, L929, and HT-22 cells, TNFa and SM-164 were used at a concentration of $10 \mathrm{ng} / \mathrm{ml}$ and $50 \mathrm{nM}$, respectively. For MEFs, TNF $\alpha$ and SM-164 were used at a concentration of $50 \mathrm{ng} / \mathrm{ml}$ and $100 \mathrm{nM}$, respectively; 100 $\mathrm{ng} / \mathrm{ml} \mathrm{TNF} \alpha$ was used to treat wild-type and FADDdeficient Jurkat cells. SM-164 was used at a concentration of $100 \mathrm{nM}$ to treat wild-type Jurkat cells. Nec-1s, GSK872, NSA, zVAD, 5Z-7, TPCA-1, and AP20187 were used at $10 \mu \mathrm{M}, 10 \mu \mathrm{M}, 2 \mu \mathrm{M}, 20 \mu \mathrm{M}, 2.5 \mu \mathrm{M}, 10 \mu \mathrm{M}$, and $20 \mathrm{nM}$, respectively. TRAIL were used at a concentration of 100 $\mathrm{ng} / \mathrm{ml}$. Identical concentrations were used as describe above, unless otherwise stated. DMSO $(<0.2 \%)$ was used as a vehicle-only control.

\section{Plasmid construction}

Human and mouse ІкB $\alpha$ were generated by PCR amplification from the cDNA of HT-29 cells and MEFs, respectively, and then cloned into the pMSCV vector or a lentiviral vector made in-house. The S32A/S36A double mutant or $\mathrm{K} 21 \mathrm{R} / \mathrm{K} 22 \mathrm{R}$ double mutant ІкB $\alpha$ were created by PCR-based site-directed mutagenesis. To construct the dimerizable MLKL, human MLKL and FKBP were amplified from cDNA of HT-29 cells. T357E/S358D MLKL and F36V FKBP were generated through PCRbased site-directed mutagenesis. The mutated MLKL, F36V FKBP, and Flag tag oligonucleotides were cloned into pMSCV vector using ClonExpress ${ }^{\mathrm{TM}}$ One Step Cloning Kit (Vazyme, Nanjing, China). The annealed shRNA and single-guide RNA (sgRNA) oligonucleotides were cloned into the pLKO.1 vector and LentiCRISPR v2 vector, respectively. All plasmids were confirmed by sequencing.

The shRNAs used in this study were selected from the RNAi Consortium (TRC) (Broad Institute, MA, USA) and are listed in Supplementary Table 1. To silence RIPK1 in MEFs, the following sgRNAs were used: sgRIPK1 \#1_Sense (S): caccgGGGTCTTTAGCACGTGCATC, sgRIPK1 \#1_Antisense (AS): aaacGATGCACGTGCTAAAGACCCc; sgRIPK1 \#2_S: caccgAGAAGAAGG GAACTATTCGC, sgRIPK1 \#2_AS: aaacGCGAATAGTTCCCTTCTTCTc; sgRIPK1 \#3_S: caccgTGTGAAAGTCACGATCAACG, sgRIPK1 \#3_AS: aaacCGT TGATCGTGACTTTCACAc.

\section{Virus packaging and transduction}

Recombinant lentivirus and retrovirus were packaged in HEK293T cells in the presence of packaging plasmids. Specifically, one well of HEK 293T cells in 6-well plates was transfected with $2 \mu \mathrm{g}$ plasmids including the expression vector and the packaging plasmids. Seventytwo hours later, the media containing the virus were collected and filtered through a 0.45- $\mu \mathrm{M}$ PVDF membrane (Millipore, Billerica, MA, USA). Transduction was performed by incubating cells with the virus-containing 
media in the presence of $8 \mu \mathrm{g} / \mathrm{ml}$ Polybrene for $48 \mathrm{~h}$. To establish the acMLKL-expressing HT-29 cells or stable cell lines expressing shRNA or sgRNA, cells were selected with $5 \mu \mathrm{g} / \mathrm{ml}$ puromycin for 3-4 days after virus transduction.

\section{RNA interference}

HT-22 cells were transfected with $50 \mathrm{nM}$ siRNA using Lipofectamin RNAiMax (Invitrogen) following the manufacturer's instruction. The sense sequence of mouse MLKL siRNA is GAGAUCCAGUUCAACGAUA.

\section{Quantitative PCR (qPCR) and semi-quantitative reverse transcription PCR (RT-PCR) analysis}

Total RNA was extracted and purified using Trizol Reagent (Thermo Fisher Scientific). Reverse transcription reactions were performed with the M-MLV reverse transcriptase (TaKaRa, Otsu, Japan). For qPCR, SYBR Green Master Mix (Vazyme) was used in StepOnePlus PCR Systems (Applied Biosystems) and the PCR conditions were $95^{\circ} \mathrm{C}$ for $10 \mathrm{~min}$, and 40 cycles of $95^{\circ} \mathrm{C}$ for $15 \mathrm{~s}$ and $60^{\circ} \mathrm{C}$ for $30 \mathrm{~s}$. Fold induction of gene expression is calculated using the $\Delta \Delta \mathrm{Ct}$ method $^{38}$. Namely, cycle threshold $(\mathrm{Ct})$ values for genes of interest were normalized to $C_{\mathrm{T}}$ values of Gapdh (human) or $\beta$-Actin (mouse) and then to that of control groups. For semi-quantitative PCR, identical reactions with polymerase (Vazyme) were performed to compare the expression level of indicated genes. PCR primers used in this study are listed in Supplementary Table 2 .

\section{polyA-selected RNA-seq}

HT-29 cells were treated with DMSO, $10 \mathrm{ng} / \mathrm{ml}$ TNF $\alpha$, or the combination of $10 \mathrm{ng} / \mathrm{ml}$ TNFo, $50 \mathrm{nM}$ SM-164, and $20 \mu \mathrm{M} \mathrm{zVAD}$ in the presence or absence of $10 \mu \mathrm{M}$ Nec-1s for $8 \mathrm{~h}$. HT-29 cells then were homogenized in a 1.5-ml tube containing $1 \mathrm{ml}$ of Trizol Reagent (Thermo Fisher Scientific). RNA isolation was followed in accordance with manufacturer's instruction. RNA was resuspended in DEPC-treated RNase free water (Thermo Fisher Scientific). TURBO DNA free kit was used to remove residual DNA contamination according to manufacturer's instruction (Thermo Fisher Scientific); $1 \mu \mathrm{g}$ of total RNA was used for sequencing library preparation. PolyA-tailed RNAs were selected by mRNA Capture Beads (VAHTS), followed by the mRNA-seq V2 Library Prep Kit for Illumina according to manufacturer's instruction (VAHTS). The library quality was examined by Bioanalyzer 2100 (Agilent). The libraries were pooled together in equimolar amounts to a final $2 \mathrm{nM}$ concentration. The normalized libraries were denatured with $0.1 \mathrm{M} \mathrm{NaOH}$ (Sigma). Pooled denatured libraries were sequenced on the illumina NextSeq 550 with single end 150 bps.

\section{RNA-seq analysis}

Sequencing reads were mapped to the reference genome hg38 with STAR2.3.0e by default parameter ${ }^{39}$. The read counts for each gene were calculated by HTSeq-0.5.4e htseq-count with parameters "-m intersection-strict -s no" ${ }^{40,41}$. The count files were used as an input to $R$ package DESeq for normalization.

\section{Immunoprecipitation}

After stimulation, the media were removed and plates were placed on ice and flooded with ice-cold PBS to stop stimulation. Cells were then lysed on ice in NP40 lysis buffer $(20 \mathrm{mM}$ Tris- $\mathrm{HCl} \mathrm{pH}$ 7.5, $150 \mathrm{mM} \mathrm{NaCl}, 1 \mathrm{mM}$ EDTA, 1\% NP40, 10\% Glycerol, $3 \mathrm{mM} \mathrm{NaF,} 1 \mathrm{mM} \beta$ glycerophophate) supplemented with the protease inhibitor cocktail (Biotool, Houston, TX, USA). Cell lysates were incubated on ice for $10 \mathrm{~min}$, and clarified at $15,000 \times \mathrm{g}$ for $15 \mathrm{~min}$ at $4{ }^{\circ} \mathrm{C}$. Lysates were then incubated with corresponding antibodies overnight, followed by incubation with the Protein G Agarose (Thermo Fisher Scientific) for $4 \mathrm{~h}$ at $4{ }^{\circ} \mathrm{C}$. After four washes with NP40 lysis buffer, the beads were boiled in SDS loading buffer (50 $\mathrm{mM}$ Tris- $\mathrm{HCl} \mathrm{pH} 6.8,2 \%$ SDS, $10 \%$ glycerol, and $100 \mathrm{mM}$ DTT) for $5 \mathrm{~min}$.

\section{Western blotting}

Cell extracts or immunoprecipitates in SDS loading buffer were subjected to SDS-PAGE. After transfer of the resolved proteins to PVDF membrane (Millipore), the membranes were blocked with $5 \%$ reconstituted dry milk in $0.1 \%$ Tween Tris-buffered saline (TBS-T) for $30 \mathrm{~min}$ at room temperature, and then successively incubated with primary antibodies overnight at $4{ }^{\circ} \mathrm{C}$ and the peroxidasecoupled secondary antibodies for $1 \mathrm{~h}$ at room temperature. Proteins were visualized by enhanced chemiluminescence substrate.

\section{In vitro kinase assay}

HT-29 cells were lysed in NP40 lysis buffer. Immunoprecipitation was performed with an anti-NEMO antibody as described above. Following three washes with 20 $\mathrm{mM}$ Tris- $\mathrm{HCl} \mathrm{pH}$ 7.5, the immunoprecipitated IKK complex was incubated with $0.01 \mathrm{mg} / \mathrm{ml}$ GST-IKB $\alpha$ (20-217) (Cat\# ag12979, Proteintech) in a kinase buffer (25 mM Tris- $\mathrm{HCl}$ pH 7.5, $10 \mathrm{mM} \mathrm{MgCl} 2,50 \mu \mathrm{M}$ ATP, 2 $\mathrm{mM}$ DTT, $5 \mathrm{mM} \quad \beta$-glycerophosphate, and $0.1 \mathrm{mM}$ $\mathrm{Na}_{3} \mathrm{VO}_{4}$ ) at $30^{\circ} \mathrm{C}$ for $1 \mathrm{~h}$. The reaction mixtures were then subjected to SDS-PAGE. The resulted phospho-GST-

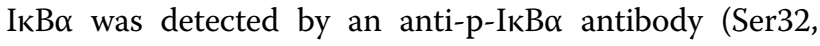
Cat\# 2859, Cell Signaling).

\section{Viability assay}

Cell survival was determined by the CellTiter-Glo Luminescent Cell Viability Assay (Promega, Madison, 
WI, USA) following the manufacturer's instruction. All cell survival assays were performed in triplicates.

\section{Flow cytometry}

The mixed cultures of mCherry and GFP-labeled HT-29 cells were stimulated with DMSO or $10 \mathrm{ng} / \mathrm{ml}$ TNF $\alpha$ (T), 50 nM SM-164 (S), and $20 \mu \mathrm{M} \mathrm{zVAD}(\mathrm{Z})$ for $6 \mathrm{~h}$. The cells were then trypsinized and separated by an Influx Cytometer (BD Biosciences) based on the mCherry and GFP expression.

\section{Immunocytochemistry}

HT-29 cells were plated on coverslips and treated as indicated. Cells were fixed with $4 \%$ paraformaldehyde and permeabilized with $0.2 \%$ Triton X-100 in PBS. Cells were then incubated with $5 \%$ bovine serum albumin in PBS for $30 \mathrm{~min}$ and the anti-p65 antibody (C-20, Cat\# sc-372, Santa Cruz) overnight at $4{ }^{\circ} \mathrm{C}$, followed by three PBS washes and subsequent incubation with the fluorescent secondary antibody for $1 \mathrm{~h}$ at room temperature. DAPI (300 nM) (Thermo Fisher Scientific) was included in the final wash for nuclei counterstain. Cells were mounted with $10 \%$ glycerol and images were acquired with a laser scanning microscope (Leica SP8 Confocal System).

\section{Sample preparation for mass spectrometry}

HT-29 cells were treated with DMSO or $10 \mathrm{ng} / \mathrm{ml}$ TNF $\alpha$ (T), 50 nM SM-164 (S), and $20 \mu \mathrm{M}$ zVAD (Z) for 4 $h$. After three washes with PBS, the culture medium was replaced with DMEM and cells were incubated for another $8 \mathrm{~h}$. The media were collected and cleared of cell debris by centrifugation. Secreted proteins in the supernatant of HT-29 culture media were concentrated with a 3-kDa centrifugal filter.

\section{Mass spectrometry}

Two-hundred micrograms of proteins from the supernatant of cell culture were trypsin digested. The resulted peptides were analyzed on Thermo Scientific Q Exactive hybrid quadrupole-Orbitrap mass spectrometer. The protein identification and quantification were done by MaxQuant $^{42}$. The tandem mass spectra were searched against UniProt human protein database and a set of commonly observed contaminants. The precursor mass tolerance was set as $20 \mathrm{ppm}$, and the fragment mass tolerance was set as 0.1 Da. The cysteine carbamidomethylation was set as a static modification, and the methionine oxidation was set as a variable modification. The FDR at peptide spectrum match level and protein level were controlled below $1 \%$. The unique peptides plus razor peptides were included for label-free quantification in MaxQuant ${ }^{43}$.

\section{GEO accession}

RNA-seq data can be downloaded from the GEO under accession number GSE 108621.

\section{Statistics}

All statistical analyses were performed using the GraphPad Prism 5. All data points are shown as mean \pm SEM unless otherwise stated. All experiments were repeated 2-3 times.

\section{Acknowledgements}

This work was supported in part by grants from the National Key R\&D Program of China (2016YFA0501900), the China National Natural Science Foundation (31530041), and the Chinese Academy of Sciences, and from the NINDS (1R01NS082257) and the NIA (1R01AG047231 and RF1AG055521) (to J.Y.), and a grant from the Natural Science Foundation of Shanghai (16ZR1443900) (to B. S.). Flow cytometry was performed at the National Center for Protein Science Shanghai.

\section{Author details}

${ }^{1}$ Interdisciplinary Research Center on Biology and Chemistry, Shanghai Institute of Organic Chemistry, Chinese Academy of Sciences, 26 Qiuyue Rd, PuDong District, 201203 Shanghai, China. ${ }^{2}$ University of Chinese Academy of Sciences, 100049 Beijing, China. ${ }^{3}$ Department of Cell Biology, Harvard Medical School, 240 Longwood Avenue, Boston, MA 02115, USA

\section{Conflict of interest}

The authors declare that they have no conflict of interest.

\section{Publisher's note}

Springer Nature remains neutral with regard to jurisdictional claims in published maps and institutional affiliations.

Supplementary Information accompanies this paper at https://doi.org/ 10.1038/s41419-018-0524-y.

Received: 19 January 2018 Revised: 6 March 2018 Accepted: 7 March 2018 Published online: 27 April 2018

\section{References}

1. Ofengeim, D. \& Yuan, J. Regulation of RIP1 kinase signalling at the crossroads of inflammation and cell death. Nat. Rev. Mol. Cell Biol. 14, 727-736 (2013).

2. Wallach, D., Kang, T. B., Dillon, C. P. \& Green, D. R. Programmed necrosis in inflammation: Toward identification of the effector molecules. Science $\mathbf{3 5 2}$, aaf2154 (2016)

3. Cho, Y. S. et al. Phosphorylation-driven assembly of the RIP1-RIP3 complex regulates programmed necrosis and virus-induced inflammation. Cell 137, 1112-1123 (2009)

4. He, S. et al. Receptor interacting protein kinase-3 determines cellular necrotic response to TNF-alpha. Cell 137, 1100-1111 (2009).

5. Wang, H. et al. Mixed lineage kinase domain-like protein MLKL causes necrotic membrane disruption upon phosphorylation by RIP3. Mol. Cell 54, 133-146 (2014).

6. Wu, J. et al. Mlkl knockout mice demonstrate the indispensable role of Mlkl in necroptosis. Cell Res. 23, 994-1006 (2013).

7. Cai, Z. et al. Plasma membrane translocation of trimerized MLKL protein is required for TNF-induced necroptosis. Nat. Cell Biol. 16, 55-65 (2014).

8. Hayden, M. S. \& Ghosh, S. Shared principles in NF-kappaB signaling. Cell 132, 344-362 (2008).

9. Ting, A. T., Pimentel-Muinos, F. X. \& Seed, B. RIP mediates tumor necrosis factor receptor 1 activation of NF-kappaB but not Fas/APO-1-initiated apoptosis. EMBO J. 15, 6189-6196 (1996).

10. Kelliher, M. A. et al. The death domain kinase RIP mediates the TNF-induced NF-kappaB signal. Immunity 8, 297-303 (1998).

11. Meylan, E. et al. RIP1 is an essential mediator of Toll-like receptor 3-induced NF-kappa B activation. Nat. Immunol. 5, 503-507 (2004).

12. Ea, C. K., Deng, L., Xia, Z. P., Pineda, G. \& Chen, Z. J. Activation of IKK by TNFalpha requires site-specific ubiquitination of RIP1 and polyubiquitin binding by NEMO. Mol. Cell 22, 245-257 (2006). 
13. Wu, C. J., Conze, D. B., Li, T., Srinivasula, S. M. \& Ashwell, J. D. Sensing of Lys 63linked polyubiquitination by NEMO is a key event in NF-kappaB activation [corrected]. Nat. Cell Biol. 8, 398-406 (2006).

14. Spencer, E., Jiang, J. \& Chen, Z. J. Signal-induced ubiquitination of IkappaBalpha by the F-box protein Slimb/beta-TrCP. Genes Dev. 13, 284-294 (1999).

15. Suzuki, H. et al. IkappaBalpha ubiquitination is catalyzed by an SCF-like complex containing Skp1, cullin-1, and two F-boxMD40-repeat proteins, betaTrCP1 and betaTrCP2. Biochem. Biophys. Res. Commun. 256, 127-132 (1999).

16. Winston, J. T. et al. The SCFbeta-TRCP-ubiquitin ligase complex associates specifically with phosphorylated destruction motifs in IkappaBalpha and betacatenin and stimulates IkappaBalpha ubiquitination in vitro. Genes Dev. 13 270-283 (1999).

17. Degterev, A. et al. Identification of RIP1 kinase as a specific cellular target of necrostatins. Nat. Chem. Biol. 4, 313-321 (2008).

18. Degterev, A. et al. Chemical inhibitor of nonapoptotic cell death with therapeutic potential for ischemic brain injury. Nat. Chem. Biol. 1, 112-119 (2005).

19. Kanehisa, M. \& Goto, S. KEGG: kyoto encyclopedia of genes and genomes. Nucleic Acids Res. 28, 27-30 (2000).

20. Kuleshov, M. V. et al. Enrichr: a comprehensive gene set enrichment analysis web server 2016 update. Nucleic Acids Res. 44(W1), W90-W97 (2016).

21. Kaczmarek, A., Vandenabeele, P. \& Krysko, D. V. Necroptosis: the release of damage-associated molecular patterns and its physiological relevance. Immunity 38, 209-223 (2013).

22. Christofferson, D. E. \& Yuan, J. Cyclophilin A release as a biomarker of necrotic cell death. Cell Death Differ. 17, 1942-1943 (2010).

23. Chen, Z. et al. Signal-induced site-specific phosphorylation targets I kappa B alpha to the ubiquitin-proteasome pathway. Genes Dev. 9, 1586-1597 (1995).

24. Zhao, J. et al. Mixed lineage kinase domain-like is a key receptor interacting protein 3 downstream component of TNF-induced necrosis. Proc. Natl Acad. Sci. USA 109, 5322-5327 (2012)

25. Vince, J. E. et al. IAP antagonists target CIAP1 to induce TNFalpha-dependent apoptosis. Cell 131, 682-693 (2007)

26. Varfolomeev, E. et al. IAP antagonists induce autoubiquitination of C-IAPs, NFkappaB activation, and TNFalpha-dependent apoptosis. Cell 131, 669-681 (2007).

27. Mandal, P. et al. RIP3 induces apoptosis independent of pronecrotic kinase activity. Mol. Cell 56, 481-495 (2014).
28. Sun, L. et al. Mixed lineage kinase domain-like protein mediates necrosis signaling downstream of RIP3 kinase. Cell 148, 213-227 (2012).

29. Lee, T. H., Shank, J., Cusson, N. \& Kelliher, M. A. The kinase activity of Rip1 is not required for tumor necrosis factor-alpha-induced IkappaB kinase or p38 MAP kinase activation or for the ubiquitination of Rip1 by Traf2. J. Biol. Chem. 279, 33185-33191 (2004).

30. Beg, A. A. \& Baldwin, A. S. Jr. The I kappa B proteins: multifunctional regulators of Rel/NF-kappa B transcription factors. Genes Dev. 7, 2064-2070 (1993).

31. Newton, $K$. et al. RIPK3 deficiency or catalytically inactive RIPK1 provides greater benefit than MLKL deficiency in mouse models of inflammation and tissue injury. Cell Death Differ. 23, 1565-1576 (2016).

32. Zhou, W. \& Yuan, J. Necroptosis in health and diseases. Semin. Cell Dev. Biol. $\mathbf{3 5}$ 14-23 (2014).

33. Ito, Y. et al. RIPK1 mediates axonal degeneration by promoting inflammation and necroptosis in ALS. Science 353, 603-608 (2016).

34. Ofengeim, D. et al. RIPK1 mediates a disease-associated microglial response in Alzheimer's disease. Proc. Natl Acad. Sci. USA 114, E8788-E8797 (2017).

35. Caccamo, A. et al. Necroptosis activation in Alzheimer's disease. Nat. Neurosci. 20, 1236-1246 (2017)

36. Harris, P. A. et al. DNA-encoded library screening identifies benzo[b][1,4]oxazepin-4-ones as highly potent and monoselective receptor interacting protein 1 kinase inhibitors. J. Med. Chem. 59, 2163-2178 (2016).

37. Harris, P. A. et al. Discovery of a first-in-class receptor interacting protein 1 (RIP1) kinase specific clinical candidate (GSK2982772) for the treatment of inflammatory diseases. J. Med. Chem. 60, 1247-1261 (2017).

38. Pfaffl, M. W. A new mathematical model for relative quantification in real-time RT-PCR. Nucleic Acids Res. 29, e45 (2001).

39. Dobin, A. et al. STAR: ultrafast universal RNA-seq aligner. Bioinformatics 29, 15-21 (2013)

40. Anders, S. \& Huber, W. Differential expression analysis for sequence count data. Genome Biol. 11, R106 (2010).

41. Anders, S., Pyl, P. T. \& Huber, W. HTSeq--a Python framework to work with high-throughput sequencing data. Bioinformatics 31, 166-169 (2015).

42. Cox, J. \& Mann, M. MaxQuant enables high peptide identification rates, individualized p.p.b.-range mass accuracies and proteome-wide protein quantification. Nat. Biotechnol. 26, 1367-1372 (2008).

43. Cox, J. et al. Accurate proteome-wide label-free quantification by delayed normalization and maximal peptide ratio extraction, termed MaxLFQ. Mol. Cell. Proteomics 13, 2513-2526 (2014) 